\title{
Numerical modeling of mechanical behavior of clinch connections at breaking out and shearing
}

\author{
Dmitri V. Berezhnoi ${ }^{1, *}$, Reza Shamim $^{1}$, and Irina S. Balafendieva ${ }^{1}$ \\ ${ }^{1}$ Kazan (Volga Region) Federal University, 18 Kremlyovskaya Street, Kazan, 420008, Russian Federation
}

\begin{abstract}
This article describes an approach to constructing the defining relationships between increment of true stresses and true deformations, with considering the contact interaction of elastoplastic deformed bodies among each other. Within the framework of finite element method, solving these problems in case of "breaking out" and "shearing" in the clinch joint, the stress fields in the zone of the clinch connection are defined, and recommendations are given for realizing the process of their creation.
\end{abstract}

\section{Introduction}

The article assigned to investigate a contact interaction structure in elastic-plastic condition. Here had brought monographs [1-6] and articles [7-22] as classical examples, it should be noted that in all these mentioned works occurs large deformations. In these problems, one of the most apprehensions to build calculation contrivance is the decomposition of total deformations or their velocities into the elastic and plastic components. As the one of the suggested methods is the additive decomposition either the velocity of deformation tensor, or the multiplicative expansion of the strain gradient tensor. However, current work is colourful considerably the problem was solved both for the axisymmetric case and for the three-dimensional state. We called three deformations of elongations and three components of shear deformations, which had shown further as true strain. The units of appropriate areas after had distorted ascribe with the true stresses. The method, which used incompletely provided in these works [23-29].

\section{Statement of the problem}

We take the components of true deformations as relative elongations of linear elements (summation over $i$ )

$$
\varepsilon_{\mathrm{ii}}=\varepsilon_{\mathrm{i}}=\left(1+2 e_{\mathrm{ii}}\right)^{0.5}-1
$$

and sinuses of the shear angles are

$$
\varepsilon_{\mathrm{ij}}=\sin \gamma_{\mathrm{ij}}=2 e_{\mathrm{ii}}\left(1+2 e_{\mathrm{ii}}\right)^{-0.5}\left(1+2 e_{\mathrm{jj}}\right)^{-0.5},
$$

where

$$
e_{\mathrm{ij}}=\left(u_{\mathrm{i}, \mathrm{j}}+u_{\mathrm{j}, \mathrm{i}}+u_{\mathrm{k}, \mathrm{j}} u_{\mathrm{k}, \mathrm{i}}\right) / 2,
$$

and $u_{i}$ - components of displacement vector. True stresses according to V.V. Novozhilov [30] are the components of stress vectors in expansion in orthonormal primary basis vectors in the deformed state of the body $\sigma_{i j}$, which through them can express the generalized (according to V.V. Novozhilov) stresses $\tau_{\mathrm{i}}$ in next equation

$$
\tau_{\mathrm{ij}}=\left(S_{\mathrm{i}} \sigma_{\mathrm{ij}}\right) /\left(S_{\mathrm{i} 0}\left(1+\varepsilon_{\mathrm{j}}\right)\right) .
$$

We can transform these relations to the form, which had written on the next line

$$
\begin{gathered}
\tau_{11}=\sigma_{11}\left(1+\varepsilon_{2}\right)\left(1+\varepsilon_{3}\right) \cos \gamma_{23} /\left(1+\varepsilon_{1}\right), \\
\tau_{12}=\sigma_{12}\left(1+\varepsilon_{3}\right) \cos \gamma_{23}=\sigma_{21}\left(1+\varepsilon_{3}\right) \cos \gamma_{13}=\tau_{21},
\end{gathered}
$$

where $S_{i}$ and $S_{i 0}$ respectively are unit of deformed area and unit of the undeformed body (indices 1, 2, 3 are interchanged cyclically), although physical relationships are written in the form between the true stresses and strains [24].

To calculate elastoplastic deformation, the HuberMises plasticity criterion was chosen in the form of

$$
\sigma_{i}-H(\varkappa)=0,
$$

where $\varkappa$ - is the scalar hardening parameter, and

$$
\sigma_{\mathrm{i}}=\left(3 s_{\mathrm{kl}} s_{\mathrm{kl}} / 2\right)^{0.5}
$$

it is the intensity of the true stresses, also components of the deviator of the true stress defined as $s_{k l}$. The relationship between increment of the components of tensor of true stress $\sigma_{i j}$ and true strain tensor $\varepsilon_{i j}$ at the stage of elastic-plastic deformation is adopted in form of the Prandtl- Reuss equations for hardening the material. For implementation of the contact interaction, the method, which used had presented in [24]. The problem was solved both for the axisymmetric case and for the three-dimensional state.

\footnotetext{
*Corresponding author: berezhnoi.dmitri@mail.ru
} 


\section{Analytical model and numerical results}

\subsection{Modling of the calculated area}

In this work, we performed a numerical simulation of the mechanical behavior for clinch joints at "breakout" and "shear" modes. The process of creating clinch connection, as well as the task of "breakout" in clinch connection are realized within the framework of the axisymmetric case, in the task of "shearing" the clinch connection based on three-dimensional analytical model. The geometry of the computational area, sketchily shown in Figure 1. The forming limit curve of steel sheet obtained as result of the experiment and shown in Fig. 2. The material from which the matrix and the punch are made is considered absolutely rigid. The coefficient of friction between the steel sheets, as well as between the die and punch, is assumed equal $\alpha_{\mathrm{f}=0.1}$.

The calculation carried out, for the case when applied, clamping force $P=9 t$. For leading in Figure 1, should know the dimensions, which presented on next line $r 1=0.013 m, r 2=0.033 m, r 3=0.07 m, t 1=0.006$ $m, r l=0.004 m$.

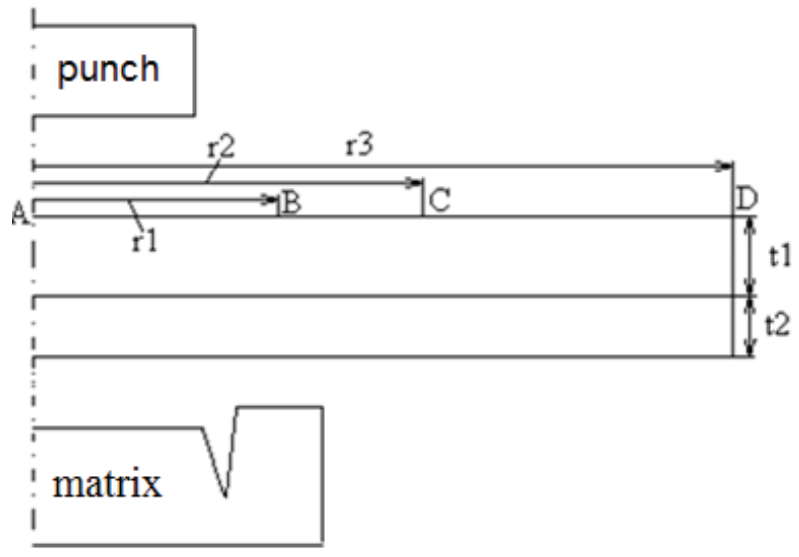

Fig. 1. Scheme of clinch connection zone.

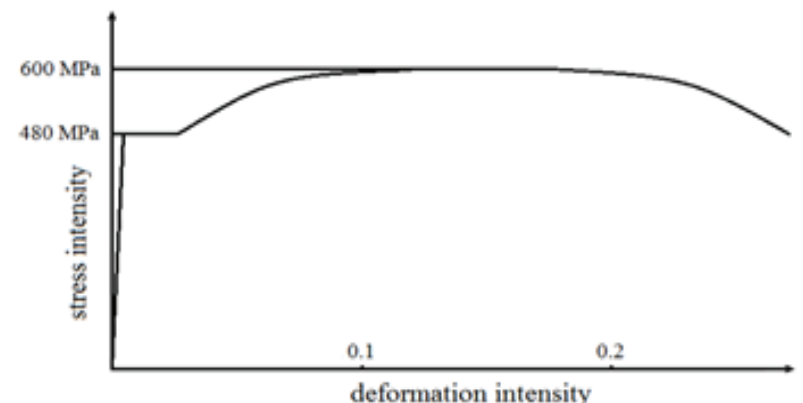

Fig. 2. The curve deformation of steel sheet material in clinch connection.

\subsection{The task of creating a clinch connection}

The task of creating a clinch-connection was solved in several stages. At the first stage, the clamping condition was reproduced in one-step. At the second stage, the punch was loaded kinematically. The loading is realized in 125 steps, loading step is $\Delta H=0.0001 \mathrm{~m}$. At the third stage of loading, the punch and matrix are removed. The punch is removed in 125 steps (its kinematic loading in the opposite direction is carried out), loading step is $\Delta H$ $=-0.0001 \mathrm{~m}$. At the fourth stage, the tension of the clamp is removed for 1 step. At the last fifth stage, the matrix is removed for 73 steps (from it the kinematic loading along the axis of the clinch joint has carried out), loading step is $\Delta H=0.0001 \mathrm{~m}$. The thickness of the neck in this case is $t=0.00089 \mathrm{~m}$, and the value of the internal groove is $f=0.00049 \mathrm{~m}$. In figure, 3 illustrated the dependence of the force in duration of its punching progress into the clinch joint made steel sheets. The maximum force in the punch measures up values $P=$ $357 \mathrm{kN}$. Figures 4 and 5 show, respectively, the intensity of the stress according to Mises and tangential stresses along the cross section of the steel sheets.

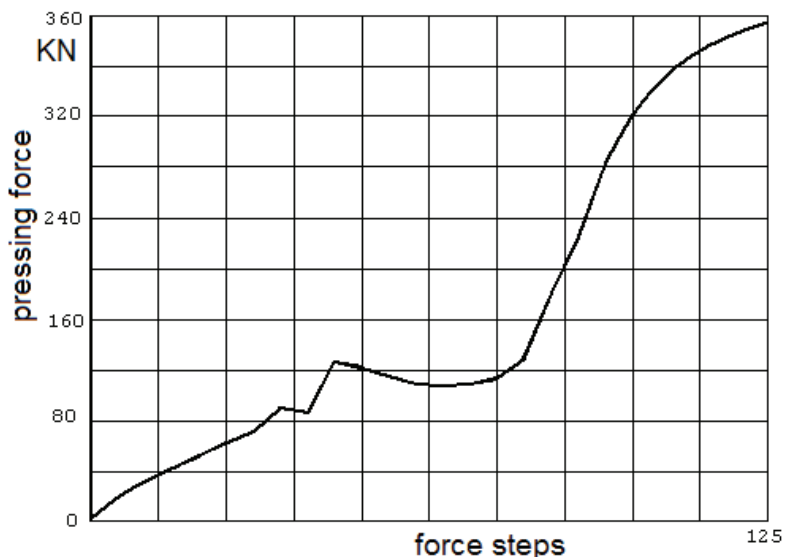

Fig. 3. Distribution of longitudinal force in the punch according to loading steps.

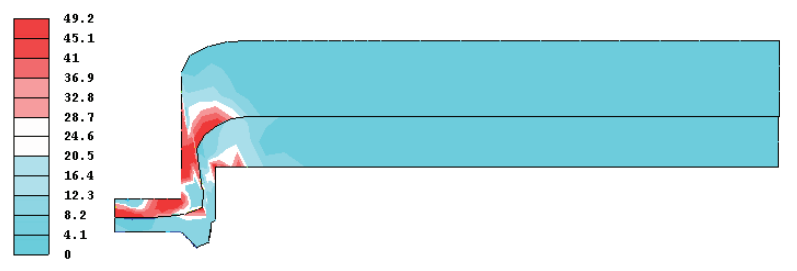

Fig. 4. Distribution of stress intensity according to Mises in the zone of the clinch joint after removal of the punch and matrix.

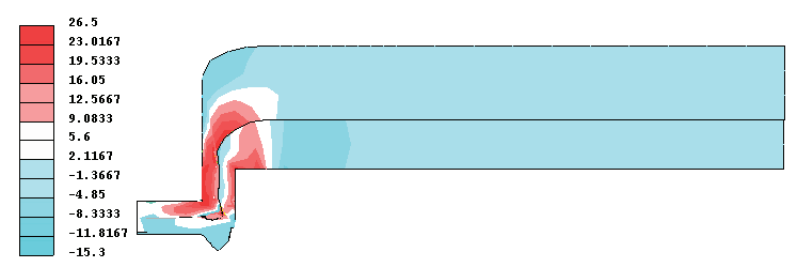

Fig. 5. Distribution of tangential stresses in the zone of the clinch joint after removal of the punch and the matrix

\subsection{The task of "breaking out" in the clinch joint}

The problem of "breaking out" in clinch joints in an axisymmetric state with considering the geometry of the clinch connection and the residual stresses on it, solved 
earlier. The lower sheet of the clinch joint is fixed, the upper sheet pulled out from it (the kinematic loading is applied on at upper surface at the top sheet). The step of kinematic loading is equal to $\Delta H=0.0001 \mathrm{~m}$. "Breaking out" duration occurs in 66 steps. Figure 6 illustrates the dependence of the value of the breaking out force in the process of separation of steel sheets from the clinch joint. Maximum pressure effort is $P_{v}=96 \mathrm{kN}$. Figures 7 and 8 show, respectively, the intensity of the stress according to Mises and tangential stresses along the cross section of the steel sheets.

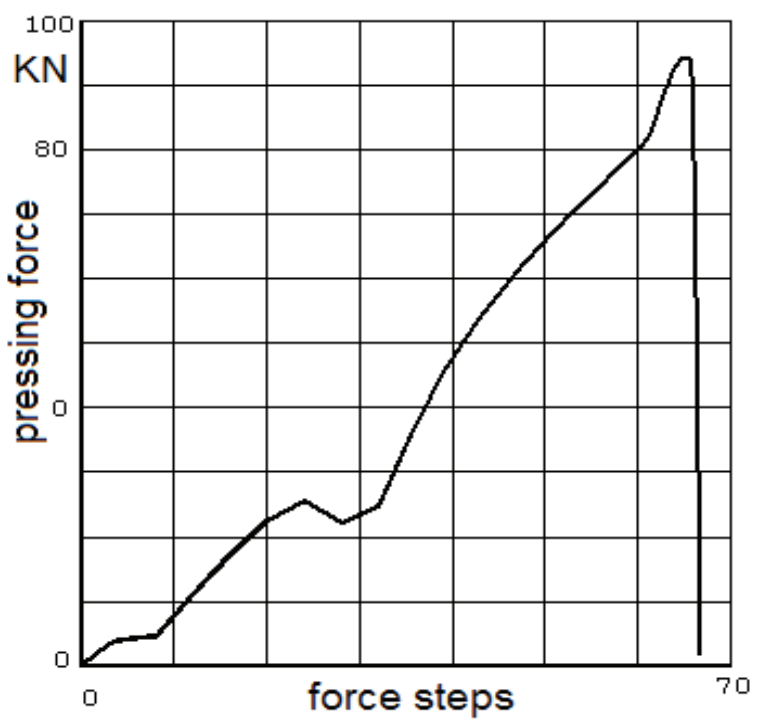

Fig. 6. Distribution of force in the "breakout" case in clinch joint by loading steps.

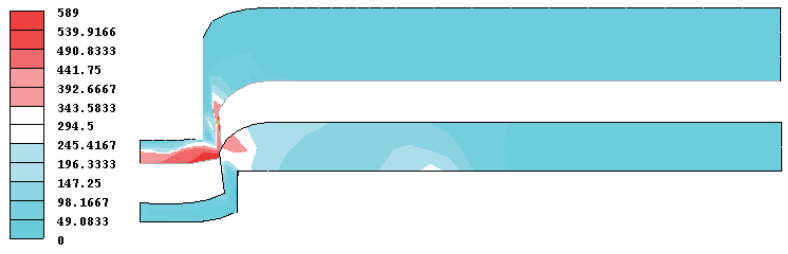

Fig. 7. Distribution of stress intensity according to Mises in the zone of the clinch joint after "breaking out" on the top sheet.

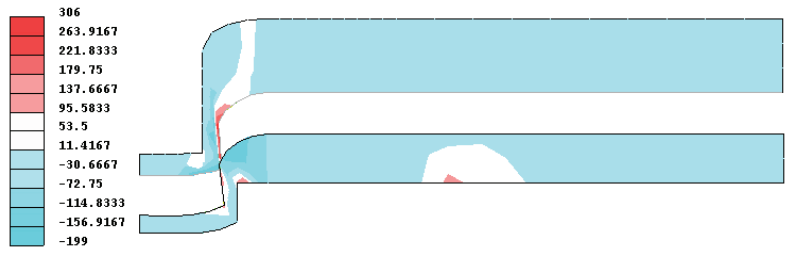

Fig. 8. Distribution of tangential stresses in the zone of the clinch joint after "breaking out" on the top sheet.

\subsection{The task of "shearing "in the clinch joint}

The task of "shearing "in the clinch joint is solved in a three-dimensional state, also solved with considering the geometry of the clinch connection and the residual stresses on it. The bottom sheet of the clinch joint is fixed, the upper one is shearing (the kinematic loading at outline points of the top sheet is specified). The step of kinematic loading is equal to $\Delta H=0.0001 \mathrm{~m}$. The shear in this case happens in 9 steps, after which the computational process diverges. This moment can be considered as disconnecting point on the clinch joint.

Figure 5 illustrates the dependence of the amount of shear force during the separation of steel sheets of the clinch joint. Maximum shear force is $P_{\mathrm{s}}=69 \mathrm{kN}$. Figures 10 and 11 show, respectively, the intensity of the stress according to Mises and tangential stresses along the cross section of the steel sheets. By way of illustration, the stresses are given for the central cross section of the clinch joint (through this cross section passes a line connecting the point of application of shearing force and the clamping point).

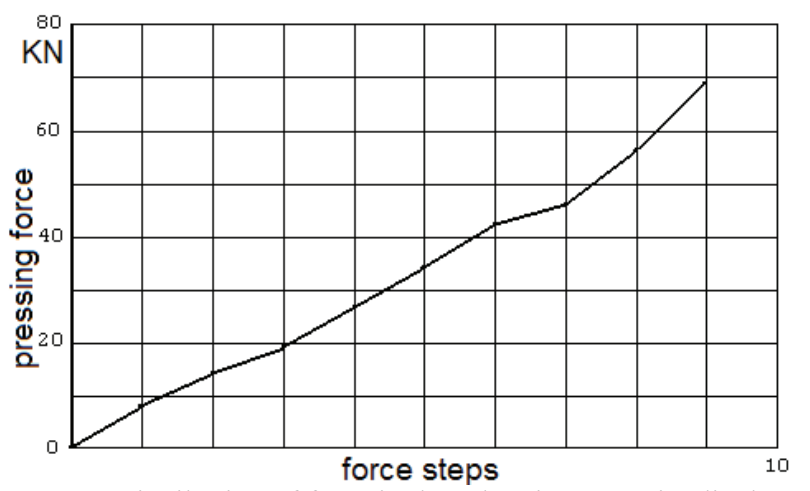

Fig. 9. . Distribution of force in the "shearing" case in clinch joint by loading steps.

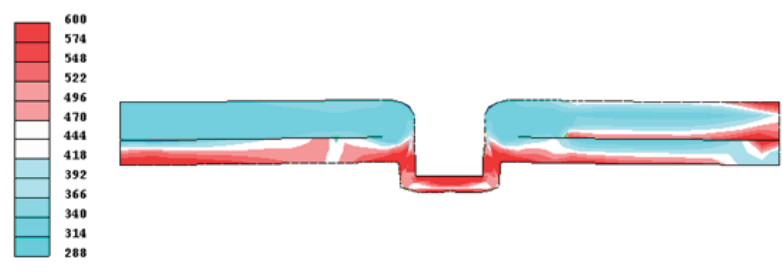

Fig. 10. Distribution of stress intensity according to Mises in the zone of the clinch joint after "shearing" on the top sheet.

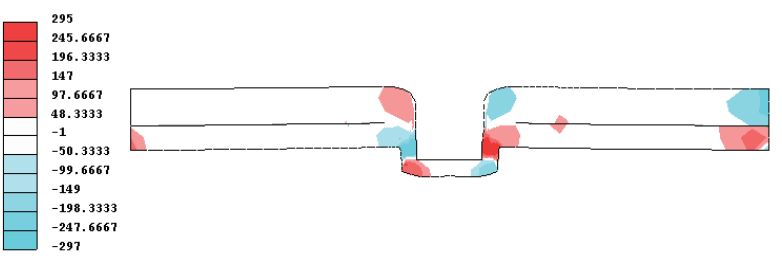

Fig. 11. Distribution of tangential stresses in the zone of the clinch joint after "shearing" on the top sheet.

\section{Analysis of results and conclusions}

For implement the creation of clinch connections, it is also not necessary to model the entire working part of the matrix: it is sufficient to know the geometry of the boundary of the upper part of the matrix. A special relation should be given for modelling the angular regions. The effect of the step size of kinematic loading on the convergence of the finite-element solution for various stages of the solution in this problem was investigated. It clarified that the value of kinematic 
loading step directly depends on the degree of sampling in the calculated area at the selected finite-element partition, the step size should not exceed from characteristic size of the height of the final element in the zone of the punch implementing. The further reduction, leads only to increase in the time of solving the problem. The effect of kinematic consolidating on the lower surface of the lower steel plate was investigated. The computational experiment showed that the availability of the kinematic boundary conditions on this part (absence of vertical displacements), provides the clamping force which is applied to the top sheet of the clinch connection, practically does not influence the solution of the problem. The effect of the pressing force amount on top sheet of the clinch joint was studied. It is noted that the clamping force in $3 t, 5 t, 7 t$ is not sufficient to ensure that the steel sheets do not disperse during the creation of the clinch joint, and by force of 14 $t$ it creates additional stress concentration zones and significantly changes the geometry of the lower steel sheet of the clinch joint.

The reported study was supported by RFBR and Government of the Republic of Tatarstan research projects No. 15-4102555, 15-41-02557.

\section{References}

1. D. Kolarov, A. Baltov, N. Boncheva, Mechanics of plastic mediums (Mir, Moscow, 1979), 302 (In Russian).

2. A.S. Sakharov, V.N. Kislooky, V.V. Kirichevski, N. Altenbach, U. Gabbert, Y. Dankert, Kh. Kepler, Z. Kochyk, The finite element method in the mechanics of solids (Higher School, Kiev, 1982), 480 (In Russian).

3. P.V. Trusov, A.I. Shveikin, The theory of constitutive relations, (Perm State Technical University, Perm, 2008), 243 (In Russian).

4. S.N. Korobeynikov, Nonlinear deformation of solids (Novosibirsk, 2000), 262 (In Russian).

5. V.I. Levitas, The large elastic-plastic deformation of materials under high pressure (Naukova Dumka, Kiev, 1987), 232 (In Russian).

6. A.A. Pozdeev, P.V. Trusov, Y.I. Nyashin, The large elastic-plastic deformation theory, algorithm, application (Nauka, Moscow, 1986), 232 (In Russian).

7. A.I. Abdrakhmanova, L.U. Sultanov, Materials physics and mechanics, 26 (1), 30-32 (2016)

8. A. Golovanov, L. Sultanov, Applied mechanics, 41 (6), 614-620 (2005)

9. R. Davydov, L. Sultanov, (DEStech publications inc., USA, 2013), 64-67.

10. L.U. Sultanov, Procedia earth and planetary science 15, 119-124 (2015)

11. R.L. Davydov, L.U. Sultanov, Journal of engineering physics and thermophysics, 88 (5), 1280-1288 (2015)
12. L.U. Sultanov, Lobachevskii journal of mathematics 37 (6), 784-790 (2016)

13. A.I. Abdrakhmanova, I.R. Gariffulin, R.L. Davydov, L.U. Sultanov, L.R. Fakhrutdinov, Applied mathematical sciences, 9 (118), 5907-5914 (2015)

14. I.B. Badriev, V.V. Banderov, G.Z. Garipova, M.V. Makarov, R.R. Shagidullin, Applied Mathematical Sciences 9 (82), 4095-4102 (2015)

15. I.B. Badriev, V.V Banderov, M.V. Makarov, V.N. Paimushin, Applied mathematical sciences, 9 (78), 3887-3895 (2015)

16. I.B. Badriev, M.V. Makarov, V.N. Paimushin, Russian mathematics 3 (59), 66-71 (2015)

17. I.B. Badriev, V.V Banderov, O.A. Zadvornov, Applied mechanics and materials), 392, 188-190 (2013)

18. I.B. Badriev, M.V. Makarov, V.N. Paimushin, Procedia engineering 150, 1056-1062 (2016)

19. O.A. Sachenkov, V.I. Mitryaikin, T.A. Zaitseva, Yu.G. Konoplev, Applied Mathematical Sciences 8 (159), 7889-7897 (2014)

20. O. Sachenkov, L. Kharislamova, N. Shamsutdinova, E. Kirillova, Yu. Konoplev, IOP Conference series, Materials science and engineering 98, 012015 (2015)

21. R.R. Galiullin, O.A. Sachenkov, R.F. Khasanov, P.S. Andreev, International journal of applied engineering research 10 (24), 44855-44860 (2015)

22. F.A. Shigapova, R.F. Mustakimova, G.T. Saleeva, O.A. Sachenkov, International journal of applied engineering research 10 (24), 44711-44714 (2015)

23. D.V. Berezhnoi, V.N. Paimushin, V.I. Shalashilin, Mechanics of solids 6 (44), 837-851 (2009)

24. D.V. Berezhnoi, V.N. Paimushin, Journal of Applied Mathematics and Mechanics 75 (4), 447-462 (2011)

25. M.K. Sagdatullin, D.V. Berezhnoi, Applied Mathematical Sciences 8 (35), 1731-1738 (2014)

26. D.V. Berezhnoi, A.A. Sachenkov, M.K. Sagdatullin, Applied Mathematical Sciences 8 (127), 6341-6348 (2014)

27. D.V. Berezhnoi, A.A. Sachenkov, M.K. Sagdatullin, Applied Mathematical Sciences 8 (143), 7107-7115 (2014)

28. D.V. Berezhnoi, I.S. Balafendieva, A.A. Sachenkov, L.R. Sekaeva, IOP Conference Series, Materials Science and Engineering 158, 012018 (2016)

29. M.R. Shamim, D.V. Berezhnoi, IOP Conference Series, Materials Science and Engineering 158, 012083 (2016)

30. V.V. Novozhilov, Fundamentals of nonlinear elasticity (Gostechizdat, Moscow-Leningrad, 1948), 211 (In Russian). 